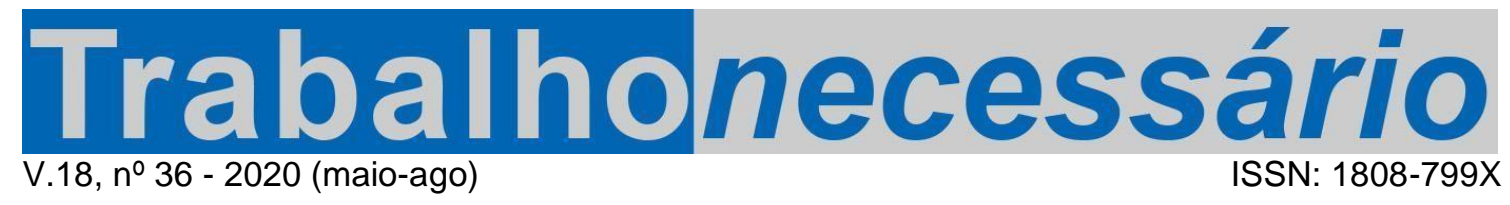

\title{
RAQUEL GUTIÉRREZ: A PESQUISADORA DO “COMUM” E DO FEMINIMO EM LUTA NA AMÉRICA LATINA ${ }^{1}$
}

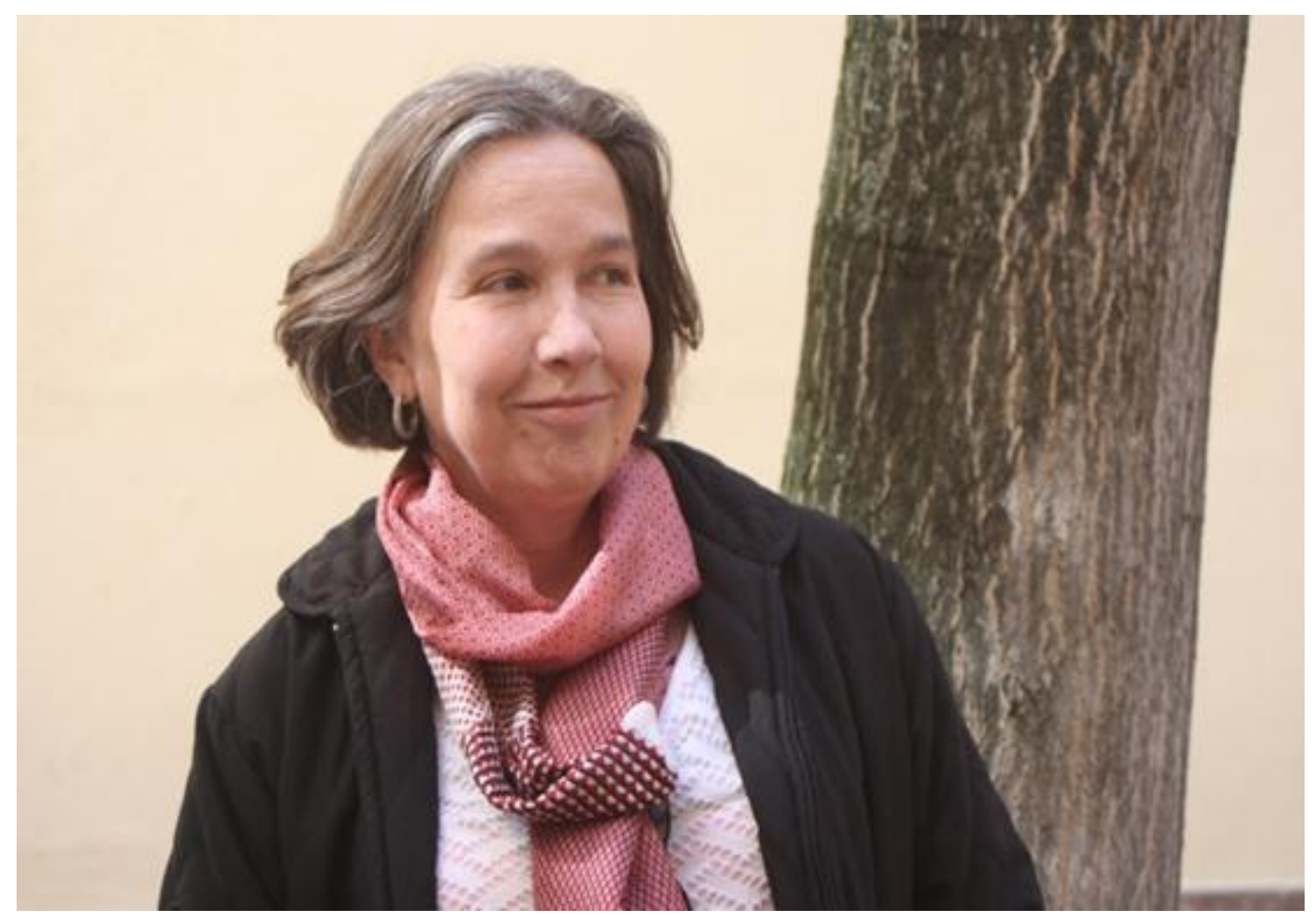

Entrevista à Raquel Gutiérrez Aguilar ${ }^{2}$ realizada por Ana Maria Motta Ribeiro (UFF) ${ }^{3}$, em 2019

${ }^{1}$ Entrevista recebida em 04/05/2020. Aprovada pelos editores em 08/05/2020. Publicada em 22/05/2020. DOI: https://doi.org/10.22409/tn.v18i36.42532

${ }^{2}$ Raquel Gutiérrez Aguilar (México, 1962) é matemática, filósofa, socióloga e activista mexicana. É profesora de sociología e investigadora del Instituto de Ciencias Sociales e Historia de la Benemérita Universidad Autónoma de Puebla especializada en movimientos indígenas en América Latina, resistencia y transformación social.

3 Professora Associada da Universidade Federal Fluminense, vinculada ao Departamento de Sociologia e Metodologia das Ciências Sociais e ao Programa de Pós-Graduação em Sociologia e Direito (PPGSD-UFF), na Linha de Pesquisa "Conflitos Socioambientais Rurais e Urbanos". Coordenadora do Observatório Fundiário Fluminense (OBFF-UFF). E-mail: anamribeiro@outlook.com ORCID: 0000-0003-2761-3539 
A autora e pesquisadora escolhida para entrevista neste número da Revista Trabalho Necessário (TN 36) foi definida a partir do tema geral: O COMUM NA AMÉRICA LATINA, de uma opção que pudesse valorizar e esclarecer o próprio sentido, atualidade e importância política deste tema no âmbito da Teoria Crítica, relativamente as condições atuais de exploração desesperada do capital que atinge de modo fatal a natureza em sua essencialidade em termos de reprodução da própria espécie humana.

O que nos levou a buscar entre pesquisadores voltados para as experiências sociais de luta e resistência contra o capital em nosso continente e que estariam acumulando simultaneamente reflexão teórica posicionada "desde abajo" e considerações empíricas focalizadas a serem reconhecidas e analisadas, dentro do rigor acadêmico necessário, pelos leitores que escolhem nosso olhar, definido por uma Linha Editorial claramente estabelecida nos parâmetros do Materialismo Histórico Dialético.

Neste sentido, foi inevitável buscar os trabalhos desenvolvidos no México da Pós Graduação de Sociologia pelo coletivo de mulheres do Instituto de Ciencias Sociales y Humanidades "Alfonso Vélez Pliego" da BUAP - Universidad Autónoma de Puebla, especificamente desenvolvido dentro de um laboratório de produção intelectual permanente em pesquisa, ensino e extensão denominado “ENTRAMADOS COMUNITÁRIOS Y FORMAS DE LO POLÍTICO” onde tive a oportunidade de atuar como Professora Visitante pela Universidade Federal Fluminense no ano de 2019, aprendendo e crescendo com o intercâmbio ali desenvolvido.

Considerando a qualidade e a originalidade dos trabalhos ali desenvolvidos e que afetaram fortemente minha trajetória e meus parâmetros na Sociologia escolhi apresentar a mais antiga e reconhecida entre elas e orientadora principal, e pouco ortodoxa, embora muito focada em termos teóricos, a professora Raquel Gutierrez.

Devo destacar que em sua qualificação, não por acaso, emergem tanto qualidades acadêmicas e termos de acúmulo considerável e admirado, como uma performance político militante destacada ao longo de seu currículo.

Curiosamente, apesar de formada nas Matemáticas superiores com louvor a sensibilidade social politizada desenvolvida ao longo de sua atuação em valorização da ciência levou precocemente seu interesse ao universo Latino 
Americano e a busca de formas de integração entre o conhecer e o transformar e desta forma em uma escolha de trabalho na Bolívia para lá se deslocou e além de uma recondução que a levou das Ciências Exatas para as Ciências Humanas onde começou a trabalhar no universo da Sociologia e da assessoria a movimentos sociais, chegando a uma importante, marcante e fundamental reflexão sobre as contradições sociais naquele país, onde finalmente, acabou por produzir uma tese de doutorado sobre o movimento inquieto dos "cocaleros" que para muito além de suas lideranças - entre elas o hoje reconhecido Evo Morales que chegou a presidência da república depois de impulsionado por lutas que ela analisou de modo magistral - destacando processos como a guerra da água; a guerra da coca como atuação imperialista e a batalha dos hidrocarburetos; destacando o protagonismo do povo Aymara e a construção de formas de autonomia e auto governo. E a posterior definição efetiva de um Estado multicultural como ascendência política, abrindo o reconhecimento sobre outras formas de direito e de definição de regras de sociabilidade possível em uma sociedade mais aberta a consideração e aceitação de sua diversidade inerente como direito formal e democrático.

Vale destacar que esses processos, que foram estudados com foco agudo por Raquel, terminaram por atingir a Universidade e sua produção, levando a própria ciência do social institucional a redefinir seus conceitos e elevando os pesquisadores da sociologia da Bolívia a um patamar que hoje eu mesma reivindico como o da melhor estirpe na produção anticolonial e antipatriarcal e contra o capital, que merece ser adotada por nossos intelectuais da teoria crítica no Brasil.

Sua obra de arranque certamente pode ser identificada no livro Los Ritmos del PACHAKUTI. Levantamiento y mobilización en Bolivia (2000-2005), Sísifo Ediciones - México, 2009. Posteriormente a este trabalho e considerando que não nos cabe subestimar a hegemonia das relações de dominação movimentadas pelo capital internacional, a conjuntura política acabou por levar Raquel e seus companheiros ao cárcere. Ficou cinco anos no total como prisioneira do Estado Boliviano. Depois de retomar sua liberdade acabou saindo da Bolívia e retornando ao México, seu país de nascimento, onde ingressou na BUAP e construiu esse coletivo a partir de sua nova e recente trajetória na sociologia, unindo-se a mais duas pesquisadoras - Mina Navarro e Lucía Linsalata, as quais apresentam artigos interessantes aqui neste número da revista. 
Na BUAP e no grupo Entramados Sociales y Formas de lo Político, cada uma dessas pesquisadoras meio que se especializam em versões do processo de construção do COMUM latino Americano. Lucía Linsalata se encontra concentrada na questão dos processos comunitários de gestão da água; Mina Navarro centra sua observação na questão do "despojo" provocado pelo capital e Raquel, caminhando devagar e respeitando os acontecimentos de rebeldia e de construção de processos libertários até para uma futura forma de organização e reprodução da vida, nos alerta, com suas escolhas, acerca das formas mais significativas e radicais de ação social contra o capital.

E assim os estudos de Raquel começam a se adensar cada vez mais pela fórmula C-P-C, como alertando para a centralidade das contradições em termos da oposição Capital-Patriarcalismo-Colonização que cada vez mais se definem como chave da reflexão crítica estratégica.

Nesta entrevista a extraordinária e politicamente sensível de Raquel Gutierrez estamos mostrando em que medida seu olhar sobre o mundo atual nos sugere que o Comum é ao mesmo tempo uma das formas de opressão mais agudas do modo capitalístico de reprodução hegemônica, e simultaneamente traz dentro dele a emergência de formas sendo gestadas no interior do próprio capitalismo como contradição, como negação concreta, a ponto de representar novas e revolucionárias formas de produção social anticapitalistas dentro do próprio capitalismo (assim como o modo burguês de produção do social se desenvolvia dentro do próprio modo feudal de dominação).

Admitindo-se, até de modo apressado, que uma interessante utopia a ser buscada poderia estar próxima de uma opção pela construção de mundo com a regência do feminino uterino e defensor da vida hoje, poderíamos levar em conta como bem vinda a vantagem de ser-estar em um mundo com essa marcação de referência. Até pensando como essa opção poderia resultar em um mundo minimamente melhor para todos e sobretudo para os homens.

A entrevista aqui apresentada e que traz a viva e segura fala aberta de Raquel Gutierrez, foi dividida em apenas três temas para que ela tivesse a maior liberdade possível de desenvolvimento de sua reflexão. Foi apenas organizada em termos de seus marcos principais relativos a defesa de um pensamento crítico estratégico, face a seu acumulo de conhecimento pensado e atuado em forma rebelde, sempre: sobre a identificação de seu trabalho coletivo e acadêmico 
militante na BUAP como "Entramados Comunitários y Formas de Lo Politico"; sobre a produção do COMUM a partir da ideia de luta social ativa; e sobre a explicação que ela desenvolve em defesa das razões teóricas e políticas de seu foco atual de trabalho sobre as mulheres dentro das tramas comunitárias que tecem o COMUM e suas decisões e imitações de luta

Sem mais nada a acrescentar, espero que tenham a melhor a mais interessante leitura dessa fantástica entrevista que nos oferece Raquel e espero ainda que entendam todo o meu elogio a seu trabalho destacando a sua relevância para o avanço de formas de superação do capitalismo em direção a um futuro melhor, mais igualitário e justo!

Trabalho Necessário: ¿Por qué, cuando fundaste un programa de investigación en una universidad pública le nombraste "Entramados comunitarios y formas de lo político"?

Raquel Gutiérrez: Si... es un nombre un poco "raro", no? A ver, en 2011 cuando llegué a trabajar a la Universidad de Puebla yo tenía la siguiente preocupación. No estaba satisfecha con la manera cómo se estaba desarrollando el debate sobre lo comunitario anclándolo en la "comunidad". Este último término siempre ha sido muy complicado y hay un gran debate, al menos en Mesoamérica y en los Andes acerca del significado de esa palabra: ¿es la comunidad una estructura cerrada de pertenencia que, a la larga, es opresiva y restrictiva? ¿Se contrapone lo comunitario a lo social que incluye aspectos más modernos de la convivencia colectiva? ¿Las comunidades son expresión de la fractura colonial de otras formas antiguas de estructuración de la vida social y constituyen sólo entidades locales de resistencia sin capacidades políticas de transformación?

Además había otro debate complicado en el cual yo había participado durante toda la década previa a llegar a Puebla que era lo relativo a la relación entre las capacidades de lucha del movimiento indígena tanto en Los Andes como acá en Mesoamérica y el contenido de la expresión "pueblos indígenas" como protagonistas de su propia auto-emancipación con base en la autonomía material y política que defendían y exigían. 
Estos asuntos, relativos al protagonismo político en lucha y a su potencia emancipativa, se contraponían y entrampaban con ciertos rasgos neoliberales que se centraban en fijar derechos específicos para "identidades" étnicamente distinguidas. Sí, me estoy refiriendo a los programas neoliberales de "reconocimiento" acotado y simplificado de derechos culturales, que era un modo maquillado de desconocer y reducir las capacidades políticas y productivas anidadas y cultivadas justamente por las comunidades indígenas. En fin... yo había participado en ese debate antes de llegar a Puebla y pretendía darle cuerpo a un programa de investigación amplio donde lograr reflexionar con calma sobre todos estos asuntos.

De ahí que por un lado, necesitaba una sustantivo no tan restrictivo como "comunidad" que pudiera aludir al protagonismo, tanto cotidiano como extraordinario, de varones y mujeres situados, que comparten maneras de sostener la vida - formas productivas, de trabajo, de uso y usufructo no organizadas por la relación de propiedad privada; a partir de las cuales tales colectividades generan formas políticas de gestión y usufructo no plenamente modernos ni capitalistas de la riqueza material de la cual disponen. Es decir, la cuestión más relevante de lo indígena, para mí, era su carácter comunitario. Carácter comunitario de prácticas materiales, productivas y políticas, que es el sostén de ricas cosmovisiones distintas al imaginario moderno. Pero veía el peligro de centrar la discusión en la diferencia étnica y, por tanto, absolutizar la diferencia, complicar la comprensión de los rasgos auto-afirmativos de la lucha étnica colapsándolos en identidades fijas y sintonizar, por tanto, con las capacidades estatales de administración de poblaciones. Mi trabajo hasta entonces se había empeñado en destacar el carácter material de la disputa entre los proyectos de modernización capitalista y la manera en que múltiples colectividades humanas en todo el continente sostienen su vida colectiva. Por todo eso comencé a pensar en los "entramados comunitarios" que es una expresión conceptual abierta que tiene, a mi juicio, dos aciertos: alude a las prácticas a partir de las cuales se producen, cuidan y conservan los vínculos entre las personas para sostener su vida material y simbólica. Es, por eso mismo, una noción dinámica que no cierra la comprensión de los sujetos en lucha. Por otra parte, al estudiar las diversas y polimorfas tramas comunitarias que habitan nuestro continente, me interesaba destacar el carácter no liberal -y en ocasiones anti-liberalde sus prácticas políticas. De ahí que el paraguas más amplio del programa de 
investigación que se inauguró en Puebla en 2011 se llamara "Entramados comunitarios y formas de lo político".

Este acercamiento se sostenía en una perspectiva que yo llamo "problemática" para distinguirla de otras más bien "disciplinarias", es decir, inscritas en las diversas tradiciones del debate académico. Quizá mi condición de "extranjera" en el debate sociológico y antropológico, dada mi formación inicial en otras disciplinas, contribuyó a guiar el pensamiento a partir de los problemas políticos que detectaba en el propio movimiento y no tanto a seguir un cánon de debate prévio.

\footnotetext{
Trabalho Necessário: ¿Qué relación hay entonces entre tus reflexiones sobre horizontes comunitariopopulares que se abren desde y durante los momentos más intensos del despliegue de las luchas y la idea de "producción de lo común" que uds. han trabajado tanto en Puebla?
}

Raquel Gutiérrez: Esto vino después. A partir de que en Puebla convergimos tanto algunas compañeras que habíamos trabajado juntas en un proyecto autónomo de formación política desde 2008, como Mina Navarro y Lucía Linsalata, con los estudiantes de posgrado cuyas investigaciones comencé a acompañar - que fueron dos inicialmente: Gladys Tzul, mujer quiché de Totonicapán, Guatemala y Huaskar Salazar de Cochabamba, Bolivia - el trabajo de reflexión adquirió mayor densidad.

Una de mis preocupaciones centrales era lo relativo a los horizontes de transformación política y social impulsados desde la experiencia de las luchas de Bolivia de principios de siglo y, sobre todo, de lo que habían podido avanzar en términos de recomposición de la vida política en ese país entre 2006 y 2009, en el primer período del gobierno Del Mas durante la Asamblea Constituyente. Para entonces yo distinguía con mucha claridad dos horizontes de transformación distintos y tendencialmente contrapuestos - ojo, no necesariamente contrapuestos en el sentido lógico de esa expresión, sino tendencialmente contradictorios a partir del gran proceso de construcción de estado-nación que desplegó el MAS a partir de 2009. Uno de ellos, el que a mí me interesaba comprender y apuntalar es el 
horizonte comunitario-popular de transformación social que había visto brotar en los momentos más enérgicos de la lucha social en Bolivia.

Este horizonte impugnaba creencias añejas de la política liberal de la modernidad-capitalista; por ejemplo, la idea de que toda política de representación tiene que organizarse en torno a mecanismos de delegación de la voluntad colectiva en mandantes que se separan y autonomizan de aquellos a quienes representan.

La delegación de la capacidad política de intervenir en los asuntos públicos "que a todos incumben porque a todos afectan", como se decía insistentemente en los tiempos de la Guerra del Agua en Cochabamba en 2000 era, para mí, el rasgo que había sido puesto en crisis por la lucha y se trataba de pensar la recomposición política en Bolivia -en particular- desde la clave del protagonismo político de las colectividades en lucha. Este horizonte cuyos rasgos críticos se mostraban intermitentemente en el escenario político, chocaban con otro horizonte "nacionalpopular" de construcción de estado y relanzamiento de nuevos ciclos de acumulación del capital que se presentaba como la única forma de lo político.

Estoy hablando de un problema que luego se ha presentado en todos los países que es entender cómo los gobiernos progresistas fueron expropiando la fuerza de las luchas sociales que los llevaron al gobierno y sustituyendo las capacidades políticas construidas desde abajo a través de nuevos procesos de disciplinamiento social, vía inclusión - subordinada - por consumo, reconocimiento acotado de derechos, etc.

Así, a mí me ha preocupado desde hace décadas, esta tensión política entre proyectos contradictorios de reorganización de la vida social y política de las colectividades humanas. La hipótesis sobre la que trabajé muchos años es que un horizonte comunitario popular puede desplegar simultáneamente prácticas de lucha no estado céntricas, y no necesariamente anti-estatales.

El corazón de la contradicción la encontramos en la capacidad colectiva de producción de lo común que alude, sin separación, a los colectivos procesos productivos de riqueza material -cuidado y uso del agua, del bosque, de las semillas, de los territorios, etc.- que son gestionados y usufructuados por colectividades que producen sus normativas internas. Hablamos entonces de procesos que consideramos simultáneamente productivos y políticos, esto es, donde la separación entre economía y política propia del capitalismo todavía no acontece plenamente. 
Este abanico de acciones prácticas de hombres y mujeres, asentadas en lo cotidiano y que tienen contenidos políticos específicos, por lo general son agredidos y se confrontan con las formas políticas liberales progresistas o de derecha -todas ellas levantadas sobre el desconocimiento radical de las capacidades políticas locales- que echan a andar proyectos productivos distintos: aquellos que no se organizan en torno a la garantía de sustento, a la reproducción de la vida en su amplia gama de procesos y necesidades, sino que se orientan a relanzar nuevos bucles de acumulación de capital; siempre prometiendo, eso sí, a futuro, una "vida mejor".

Esta multifacética tensión antagónica, esto es, la diversificada manera como aparecía en muchísimas experiencias que fuimos estudiando, además de la interlocución con dos vetas de pensamiento que han sido importantes para nosotras: el pensamiento feminista materialista de Silvia Federici y la tradición de la comunalidad tal como se practica en los pueblos indígenas de Oaxaca, México según lo expresa Jaime Martínez Luna; nos empujaron a pensar la producción de lo común como categoría crítica y como relación social. Es decir, entendemos "lo común" como un tipo de relación social, que alude a procesos productivos y políticos que se desarrolla más allá, contra y más allá de la relación del capital. En tal sentido, lo común es un modo específico de organizar las relaciones entre las personas, entre las personas y la riqueza material de la que disponen y dos de sus hilos centrales son la reciprocidad y la autodeterminación. Estas ideas nos permitieron volver a la investigación sobre los horizontes de transformación con mejores herramientas teóricas.

Trabalho Necessário: ¿Y las luchas de las mujeres dentro de las tramas comunitarias? ¿Por qué ahora le dan tanta importancia a su estudio y acompañamiento?

Raquel Gutiérrez: Desde más o menos 2011 comenzamos a documentar un rasgo en diversas luchas de defensa territorial contra los "despojos múltiples" -como dice Mina- de los que eran objeto: el protagonismo femenino en el comienzo de las luchas. Aquí y allá comenzamos a encontrar que eran las mujeres que habitan y sostienen las tramas comunitarias quienes, con frecuencia, a partir de alguna acción tremendamente radical: poner el cuerpo para impedir el paso de las máquinas, 
confrontación enérgica con los grupos de sicarios que con frecuencia protegen los procesos extractivistas de despojo, etc. Fuimos rastreando tres hilos en esta constelación de sucesos de lucha: el protagonismo femenino en lucha para alterar las condiciones del despojo, la enunciación de sus acciones como "luchas en defensa de la vida" $y$, también, la enorme dificultad que confrontaban esas compañeras en lucha tanto para sostener sus deliberaciones, puntos de vista y anhelos a lo largo del tiempo como el entrampamiento de sus esfuerzos, al interior del propio tejido comunitario, en medio de instancias organizativas y políticas de producción de decisión que o bien las excluían o bien no las incluían de modo equilibrado. Esto es, comenzó a hacerse evidente para nosotras un añejo problema que ahora se exhibía con claridad: la estructuración patriarcal de lo social, también en las tramas comunitarias, boicoteaba y a veces suprimía el protagonismo de las mujeres en lucha. Esto por una parte, por la otra, desde 2015, ante la abismal espiral de violencia conexa tanto con los procesos de despojo como con la conculcación de las capacidades políticas cultivadas desde la sociedad, se disparó la epidemia de feminicidios y violencia extrema contra las mujeres que actualmente enferma a todas nuestras sociedades.

También comenzamos a documentar las luchas contra tales situaciones que se desplegaban en territorios y barrios. Identificamos dos torrentes de protagonismo de las mujeres, que son distinguibles pero no plenamente diferentes: luchas en defensa de la vida y luchas contra todas las violencias machistas. Entonces nos decidimos a aprender de tales procesos, a reflexionar desde lo que se iba haciendo y desde las dificultades que se iban confrontando. De ahí comenzamos, igual que antes, a esforzarnos por ubicar los problemas para nombrarlos y reflexionar sobre ellos. El torrente de luchas contra todas las violencias se amplificó inmensamente a través de las nuevas formas organizativas y de disputa por el sentido de los sucesos sociales, sobre todo desde el Cono Sur del continente. Aunque en cada país y en cada región esta energía de lucha comenzó a reverberar renovando las luchas y abriendo el actual momento de rebelión feminista donde se guarda y se cuida la esperanza y los ánimos de transformación en momentos turbulentos y, a veces, muy trágicos y tristes.

Comenzamos entonces a estudiar no sólo los diversos debates que amplísimas reflexiones feministas habían puesto en la discusión pública en los últimos años, sino que también rastreamos los hilos de anteriores luchas feministas. 
De tal manera fuimos entretejiendo en nuestros argumentos sobre la producción de lo común el álgido tema de las luchas contra los rasgos patriarcales que organizan el mundo público y también reducen los rasgos políticos instituidos al interior de las propias tramas en lucha. Esta tarea, en la que por ahora yo sigo inmersa nos ha abierto otros tantos terrenos de reflexión.

Por lo demás, el programa de Entramados comunitarios se ha nutrido ampliamente de los aportes del debate sobre Ecología política, empujado al interior de nosotras sobre todo por Mina. Volver sobre nuestras iniciales intuiciones y reflexiones sobre las tramas comunitarias que garantizan la reproducción de la vida y politizan sus acciones desde ahí, ahora a la luz de claves como la interdependencia de lo humano y lo no humano, atendiendo a los diversos ciclos metabólicos que se combinan y superponen cuando se atiende al proceso general de reproducción de la vida humana y no humana, está siendo muy fértil ya que nos permite extender nuestras conversaciones también hacia otros debates que, bajo otras pautas, se presentan de manera muy fragmentaria y sobre todo, muy despolitizada. Diversas compañeras están ahora reflexionando y trabajando sobre estas temáticas tanto en Bolivia, en Uruguay y en México. Hay una constelación de jóvenes investigadoras como Itandehui Reyes, Vanessa Carsolio y Ana Lilia Salazar en México, Claudia López, Claudia Cuellar, Dunia Mokrani en Bolivia, Mariana Menéndez, Noel Sosa y otras colegas en Uruguay.

Trabalho Necessário: Volviendo a la cuestión de los horizontes políticos, ¿Cómo entienden los contenidos de los horizontes comunitario-populares?

Raquel Gutiérrez: Esa es una pregunta complicada porque para atender a los contenidos comunitarios de transformación se necesita, a mi modo de ver, una mirada no estado-céntrica de la política y lo político. Es decir, si se concede -tal como impone el pensamiento moderno y patriarcal- que toda actividad política pasa necesariamente por el estado, entonces no puede tocarse ni comprenderse la fuerza de la politicidad comunitaria y mucho menos entender sus rasgos críticos más filosos. Ahora bien, situar la comprensión de lo político desde lo no estadocéntrico, no quiere decir no saber -o ignorar- que el estado es también una forma política de monopolización de la producción de decisiones así como la imposición- 
expansión de mecanismos administrativos de la riqueza material y de las personas. $Y$ que eso tiene que ser tomado en cuenta siempre, tanto en las luchas como en las reflexiones sobre la transformación social que se hace en deliberación con quienes están luchando.

Nosotras hemos acuñado una formulación que, a mi juicio no es tan afortunada pues no tiene la virtud de la sencillez, pero que al menos, por ahora, ayuda a esclarecer cuestiones difíciles que hacen al pensamiento a contrapelo: contra las certezas heredadas de la modernidad $y$, sobre todo, de las tradiciones políticas de izquierda del siglo XX. La formulación que ensayamos y sobre la que vamos reflexionando es la siguiente: consideramos que un horizonte comunitariopopular de transformación es, en primer lugar, necesariamente plural. No se organiza en torno a la síntesis de un programa sino que se desparrama en todo el cuerpo social como lucha con vocación de generalización y enlace. Desde ahí decimos que la política que se practica bajo un horizonte comunitario-popular es no estado céntrica y no necesariamente anti estatal.

Diego Castro, un colega uruguayo que se graduará en unos meses, es quien más ha avanzado en esta reflexión sobre todo registrando la historia más o menos reciente del Uruguay - los últimos 50 años - explorando los esfuerzos y acciones más potentes del tejido sindical de ese país por subvertir la pesada herencia de la política estado-céntrica de izquierda, ligada íntimamente a horizontes de construcción de estado -y por tanto de monopolización de las capacidades políticasque, casi de manera inmediata, amarran lo político al "desarrollo", es decir, a la garantía no del sostén de la vida colectiva sino a nuevos procesos de acumulación del capital.

\section{Alguna bibliografía:}

NAVARRO, M. L. Luchas por lo común: antagonismo social contra el despojo capitalista de los bienes naturales en México, ICSYH-BUAP/Bajo Tierra ediciones, Ciudad de México, 2015.

LINSALATA, L. Cuando manda la asamblea. Lo comunitario-popular en Bolivia: una mirada desde los sistemas comunitarios de agua de Cochabamba, SOCEE-Autodeterminación-Fundación Abril, Cochabamba, 2015. 
SALAZAR, H. Se han adueñado del proceso de lucha. Horizontes comunitariopopulares en tensión y la reconstitución de la dominación en la Bolivia del MAS, SOCEE-Autodeterminación, Cochabamba, Bolivia, 2015.

TZUL, G. Sistemas de gobierno comunal indígena. Mujeres y tramas de parentesco en Chimeq'ena', SOCEE-TZ'I'KIN-MAYA'WUJ, Guatemala, 2016. 